\title{
Numerical modeling of the response of Ceará continental shelf waters to wind stress forcing
}

\author{
Jacyra Soares $^{1}$ \& Belmiro Mendes de Castro Filho ${ }^{2}$ \\ ${ }^{1}$ Instituto Astronômico e Geofísico da Universidade de São Paulo \\ (Rua do Matão, 1226 - 05508-900, São Paulo, SP, Brasil) \\ ${ }^{2}$ Instituto Oceanográfico da Universidade de São Paulo \\ (Caixa Postal 66149, 05315-970 São Paulo, SP, Brasil)
}

\begin{abstract}
- Abstract: Ceará shelf waters response to steady and transient wind forcing, from Ponta Cajuais $\left(04^{\circ} 42^{\prime} \mathrm{S}, 37^{\circ} 19.5^{\prime} \mathrm{W}\right)$ to Ponta de Itapagé $\left(02^{\circ} 50.5^{\prime} \mathrm{S}, 40^{\circ} 00^{\prime} \mathrm{W}\right)$, was studied using a hydrodynamic numerical model. The finite difference model was based upon the equations for a barotropic ocean in general form: advective and quadratic surface and bottom stress terms were included. Seasonal differences in the shelf waters response were characterized by simulation of summer and winter forcing. Such experiments were conducted for both $f$ and equatorial beta plane domains, without significative differences in the results. Transient shelf waters response were investigated using surface winds from the Fortaleza airport, during the period extending from 14/03 to 25/03/79. Model results were compared to current data collected during the same period; modeled currents were able to roughly describe observed current pattern, but not current intensity.
\end{abstract}

- Resumo: A resposta das águas da plataforma continental do Ceará, de Ponta Cajuais $\left(04^{\circ} 42^{\prime} \mathrm{S}, 37^{\circ} 19,5^{\circ} \mathrm{W}\right)$, à forçante do vento estacionária e transiente foi estudada através de um modelo numérico hidrodinâmico. $O$ modelo, na forma de diferenças finitas, utiliza as equaçōes do movimento e da continuidade de massa para um oceano barotrópico no caso mais geral: estão incluídos os termos advectivos, bem como o atrito com o fundo e a tensão de cisalhamento do vento, ambos parametrizados na forma quadrática. Variaçōes sazonais na resposta estacionária das águas da plataforma continental, da área estudada, foram caracterizadas pela simulação das condições de verão e inverno da região. Os experimentos foram realizados no plano f e no plano $\beta$ equatorial sem diferenças significativas nos resultados. A resposta transiente das águas da plataforma continental, da região escolhida, foi investigada usando uma série temporal de vento de superfície do Aeroporto de Fortaleza do período de 14 à 25 de março. O período escolhido para a simulação coincide com o período em que há dados observados de corrente na região. A corrente modelada descreveu o padrāo da corrente observada mas não sua intensidade.

- Descriptors: Wind-driven currents, Sea level, Ceará continental shelf.

- Descritores: Correntes induzidas pelo vento, Nível do mar, Plataforma continental do Ceará.

\section{Introduction}

Due to the importance on climate, transport and general circulation of properties, the oceanic equatorial region of the western Atlantic Ocean has been focus of several international experiments of Meteorology and Oceanography, such as TOGA, SEQUAL and FOCAL.

Contr. no. 802 do Inst. oceanogr. da Usp.
In contrast, the equatorial coastal region of the Atlantic Ocean, particularly that localized along the coast of South America, is one of the less studied regions of the globe. Because of the strong link between the coastal currents and practically all oceanographic phenomenon which occur on the continental shelf the knowledge of the behavior of those currents is of fundamental importance for a better comprehension of coastal environments. 
The dynamical processes occurring on shelf seas differ of those on the deep ocean. The horizontal scales of motions on the shelf are in general smaller than those of the deep ocean and the presence of the coast exerts a strong influence on the motions. The depths involved are of order of $100 \mathrm{~m}$, contrasting with those of $1000-10000 \mathrm{~m}$ in the deep ocean. Therefore, the effects of phenomenon occurring on the surface of continental shelves, such as wind and heating, may be communicated to a large fraction of the water column, sometimes to the whole column. In the deep ocean, in contrast, the same influences reach only a thin layer of the surface waters.

The wind stress exerted over the ocean surface is an important agent in the coastal ocean circulation. The wind effects can be communicated to the water column through Ekman pumping and pressure gradient forces. In the first moments the shelf water response to the wind stress is controlled mainly by the inertia of the fluid with the Earth's rotation playing an important role in the process. The maintenance of the wind stress acting on the sea surface leads, however, to a steady circulation controlled by dissipation (Csanady, 1982).

The main purpose of this work is to investigate, using a hydrodynamic numerical model, the response of the continental shelf waters of Ceará to both steady and transient wind forcing. Seasonal differences in the shelf water response are characterized by simulation of summer and winter forcing. The experiments are conducted for both $\mathrm{f}$ and $\beta$ plane domains.

The transient response is obtained using temporal series of surface wind of Fortaleza Airport, for the period of 14 to 25 March of 1979. The period chosen for the simulation coincides with the period where there are observational current data available.

\section{Geographical setting}

The studied region is localized in the northeast continental shelf of Brazil (NECS), extending from Ponta Cajuais $\left(04^{\circ} 42^{\prime} \mathrm{S}, 37^{\circ} 19.5^{\prime} \mathrm{W}\right)$ to Ponta de Itapagé $\left(02^{\circ} 50.5^{\prime} \mathrm{S}\right.$, $\left.40^{\circ} 00^{\prime} \mathrm{W}\right)$, as shown in Figure 1.

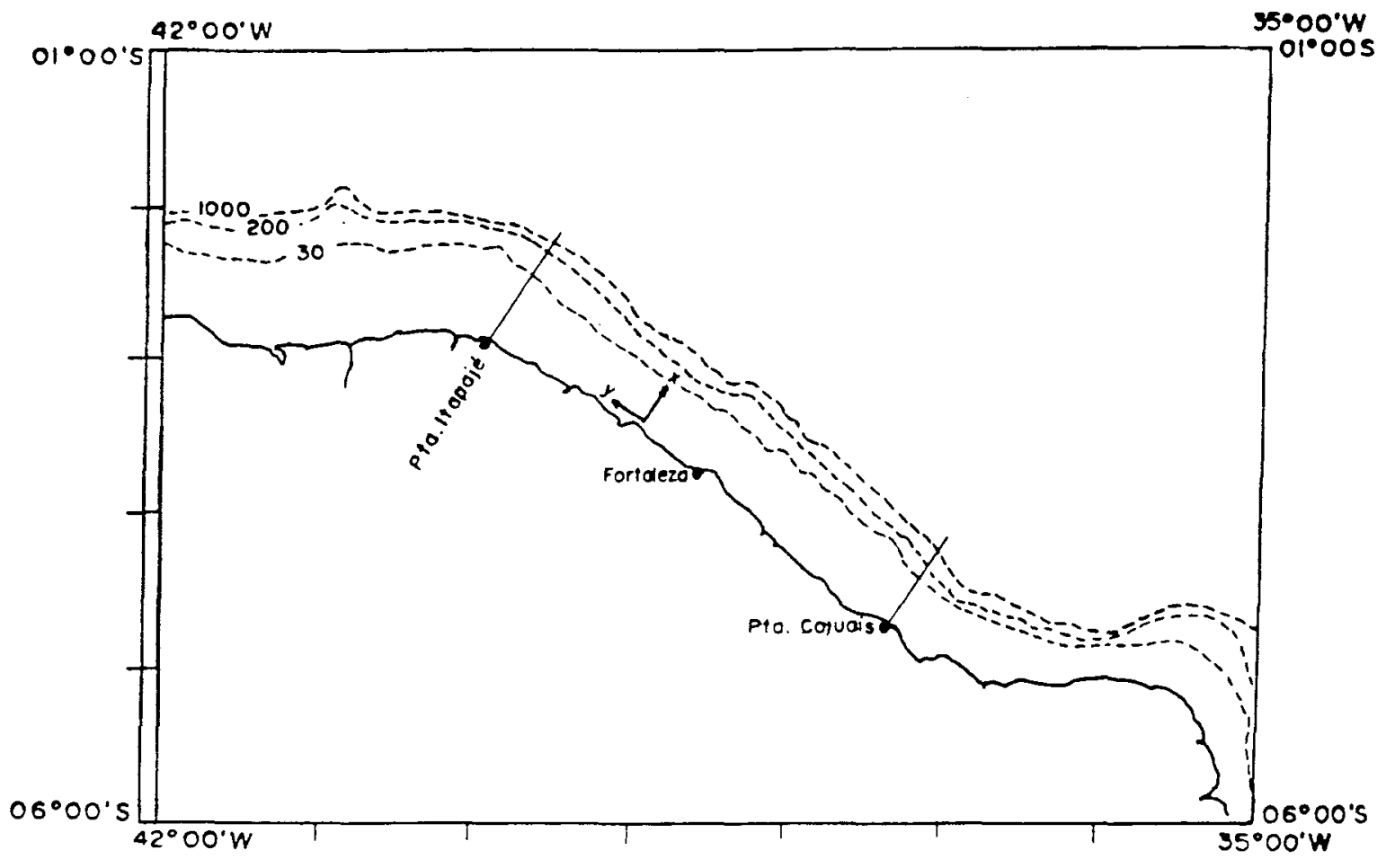

Fig. 1. Northeast coast of Brazil showing depths in meters. $X$ and $Y$ axis show the orientation used for decomposing vectors in alongshelf and cross-shelf directions. 
The general coastline orientation, in this area, is southeast-northwest, inclined approximately $55^{\circ}$ from the meridian. The distance between Ponta de Itapagé and Ponta Cajuais is around $360 \mathrm{~km}$. Shelf width is about $60 \mathrm{~km}$, being the shelf break located near the $50-80 \mathrm{~m}$ isobaths. This shelf is shallower in the eastern portion and the depths increase towards the equator. The bathymetry is uniform, showing isobaths generally parallel to the coastline.

\section{Model}

The basic equations used in the work are the momentum and continuity equations for the flow of a homogeneous ocean, as derived for example by Gill (1982):

$$
\begin{aligned}
& \frac{\partial \mathrm{u}}{\partial \mathrm{t}}+\frac{\partial\left(\overrightarrow{\mathrm{V}}^{2} / 2\right)}{\partial \mathrm{x}}-\mathrm{v}(\zeta+\mathrm{f})=-\mathrm{g} \frac{\partial \eta}{\partial \mathrm{x}}+\frac{\tau^{\mathrm{sx}}-\tau^{\mathrm{bx}}}{\mathrm{h}+\eta}+\mathrm{A}_{\mathrm{H}} \nabla^{2} \mathrm{u} \\
& \frac{\partial \mathrm{v}}{\partial \mathrm{t}}+\frac{\partial\left(\overrightarrow{\mathrm{V}}^{2} / 2\right)}{\partial \mathrm{y}}+\mathrm{u}(\zeta+\mathrm{f})=-\mathrm{g} \frac{\partial \eta}{\partial \mathrm{y}}+\frac{\tau^{\mathrm{sy}}-\tau^{\mathrm{by}}}{\mathrm{h}+\eta}+\mathrm{A}_{\mathrm{H}} \nabla^{2} \mathrm{v} \\
& \frac{\partial \eta}{\partial \mathrm{t}}+\nabla \cdot[(\mathrm{h}+\eta) \overrightarrow{\mathrm{V}}]=0
\end{aligned}
$$

Here, $\eta$ is the free surface elevation above the still water level; $h=h(x, y)$ is the still water depth; $u$ and $v$ are the horizontal components of the vector average velocity $\mathrm{V}$, in the $\mathrm{x}$ and $\mathrm{y}$ directions, respectively; $\mathrm{f}$ is the Coriolis parameter; $g$ is the gravitational acceleration; $\tau^{\mathrm{sx}}, \tau^{\mathrm{sy}}$ are the wind stress components in the $\mathrm{x}$ and $\mathrm{y}$ directions, respectively; $\tau^{\mathrm{bx}}, \tau^{\mathrm{by}}$ are the kinematics bottom stress components in the $\mathrm{x}$ and $\mathrm{y}$ directions, respectively; $\mathrm{A}_{\mathrm{H}}$ is a coefficient of kinematics horizontal eddy viscosity, assumed to be constant $A_{H}=10 \mathrm{~m}^{2} \mathrm{~s}^{-1} ; \zeta$ is the relative vorticity.

The depth averaged currents $u$ and $v$ are defined by:

$$
u=\frac{1}{(h+\eta)} \int_{-h}^{\eta} u^{\prime} d z \text { and } v=\frac{1}{(h+\eta)} \int_{-h}^{\eta} v^{\prime} d z
$$

where $u^{\prime}, v^{\prime}$ are the components of the currents at depth $z$.

The wind stress magnitude is specified by a quadratic drag law: $\tau^{\text {si }}=\left(\rho_{\mathrm{a}} / \rho_{\mathrm{w}}\right) \mathrm{C}_{10} \mathrm{~W}_{\mathrm{i}} \mathrm{W},(\mathrm{i}=\mathrm{x}, \mathrm{y})$, where $\rho \mathrm{a}$ and $\rho_{\mathrm{W}}$ are the air and water densities, respectively; $\mathrm{C}_{10}$ is the drag coefficient and $W$ is the wind speed measured at a height of $10 \mathrm{~m}$ above the sea level. The drag coefficient was used as suggested by Large and Pond (1981): $10^{3} \mathrm{C}_{10}=1.2$ (for $4 \leq \mathrm{W}<11 \mathrm{~m} \mathrm{~s}^{-1}$ ) or $10^{3} \mathrm{C}_{10}=0.49+0.065 \mathrm{~W}$ (for $11 \leq \mathrm{W}<25 \mathrm{~m} \mathrm{~s}^{-1}$ ).

The bottom stress is also expressed by a quadratic law: $\tau^{b i}=c_{d} u_{i}\left(u^{2}+v^{2}\right)^{1 / 2},\left(i=x, y ; u_{i}=u, v\right)$, where $c_{d}$ is the bottom drag coefficient. A constant $c_{d}=0.003$ is used throughout the experiments.
The use of a barotropic model is justified by the thermohaline field observations (DHN, 1968) and by the current field in the region (Signorini \& Miranda, 1983). Both fields exhibit quasi-barotropic characteristics in the region.

\section{Finite-difference scheme}

Equations (1)-(3) were discretized using a Richardson Lattice grid ("C" grid of Mesinger \& Arakawa, 1976).

In this grid variables are staggered horizontally as follows: surface elevation, wind stress, bottom stress, lateral stress and depth occupy the same set of grid points, whereas the velocity components $u$ and $v$ are defined half-way in $x$ and y directions, respectively, between those grid points.

The time discretization scheme, used in this work, was developed by Castro Filho (1985) and it is a modification of the traditional forward-backward (FB) scheme: the gravity terms - sea level gradient terms in the momentum equation and divergence term in the continuity equation - of equations (1)-(3) were discretized using a FB scheme. The advection and Coriolis terms of the momentum equations were centered in time using the Adams-Bashforth (AB) scheme. The stress and viscous terms were lagged in time, as usual, in order to keep the system stable.

The FB scheme is obtained by first integrating the gravity terms of either the equation of motion or of the continuity equation forward, and then those of the other equation. Mesinger \& Arakawa (1976) have studied the stability and convergence of this scheme in the context of the linearized shallow-water equations. The stability limit for the time step is twice the Courant-Friedrichs-Lewy condition valid for other discretization schemes, like the leapfrog for example, which makes this scheme very attractive in terms of computing efficiency. In addition, as a two level scheme, it has no computational mode in time.

Henry (1981) and Foreman (1984) showed, using linearized shallow water equations, that the application of the FB scheme for both the gravity wave terms and the Coriolis terms introduces phase velocity error for the long waves present in the model. In order to avoid these phase velocity error, generated by asymmetric treatment of Coriolis terms, the Coriolis terms were centered in time using the $A B$ scheme. Since it is desirable to have the advective terms also centered in time, both the advection and Coriolis terms are collected together and the $A B$ scheme was used to center the combined terms in time.

The AB scheme used here, a second order accurate version (Mesinger \& Arakawa, 1976) is a simplified version of the original scheme, which is of fourth order of accuracy. 
Initial and boundary conditions: The basin was excited from an initial resting state in all experiments, i.e., initial conditions were $\eta=u=v=0$ in all grid points. An impulsive wind stress was suddenly applied at all grid points at $t=0$.

The following set of boundary conditions was chosen to be used in the model boundaries:

(i) Land-sea boundary: no normal flow across the boundary;

(ii) Cross-shelf open boundaries: radiative boundary condition;

(iii) Alongshelf open boundary: adiabatic boundary condition.

The radiative boundary condition follows Castro Filho (1985) and is a modification of Orlanski's radiative boundary condition (Orlanski, 1976). The idea is that close to the boundaries the dependent variables satisfy the equation:

$$
\frac{\partial \mathrm{A}}{\partial \mathrm{t}}+\mathrm{c} \frac{\partial \mathrm{A}}{\partial \mathrm{T}}=0
$$

where $A$ is the dependent variable, $c$ is the phase velocity and $r$ is the direction. The above equation can be discretized in a form compatible with the numerical scheme described in the previous section:

$$
\frac{A^{n+1}(B)-A^{n}(B)}{\Delta t}+c_{B} \frac{A^{n}(B)-A^{n}(B-1)}{\Delta r}=0
$$

where $\Delta r$ is equal to either $\Delta x$ or $\Delta y$, depending which direction ( $\mathrm{x}$ or $\mathrm{y}$ ) is normal to the boundary; $\mathrm{B}$ indicates a point on the boundary, B-1 is the first point inside that boundary and $n, n+1$ indicate consecutive time levels. Since $A^{n+1}(B)$ is the unknown of the problem, $c$ is actually evaluated at the point $B-1$ :

$$
c_{B-1}=\frac{\Delta r}{\Delta t} \frac{\left[A^{n+1}(B-1)-A^{n}(B-1)\right]}{\left[A^{n}(B-1)-A^{n}(B-2)\right]}
$$

Equation (6) is used to estimate the phase velocity of the waves approaching the boundary. The phase velocity is then extrapolated to the boundary in order to find $A^{n+1}(B)$ from equation (5). The values allowed for the estimated phase velocity are in the interval $(0, \Delta r / \Delta t)$. If the velocity is negative, as in the case of a wave penetrating the boundary from outside the domain, the value of the dependent variable is extrapolated from the previous time step. If the estimated velocity is larger than $\Delta r / \Delta t$ then it is set equal to
$\Delta r / \Delta t$, since numerically this last value corresponds to the fastest wave that the model can handle.

In all the experiments the cross-shelf open boundaries were located along lines where the velocity normal to that boundary is defined. With this placement of the cross-shelf open boundaries there is always only one dependent variable located on the open boundary for each grid mesh: the $v$ velocity component. Equations (5) and (6) were applied only to this dependent variable.

The other two dependent variables (sea level and the $u$ velocity component) were calculated using equations (1)-(3) since that they are actually located inside the model domain.

The adiabatic boundary condition consists of keeping the sea level constant, $\eta=0$, for example. In order to alleviate the shortcomings of this condition (it is a reflective boundary condition and can artificially generate cross-shelf pressure gradient) and to make that boundary more realistic the alongshelf open boundary was positioned far from the shelf break, into the deep ocean, at depths always exceeding $900 \mathrm{~m}$.

Spatial and temporal resolution: The grid uses coordinates rotate $51,5^{\circ}$ to the west to better adjust itself to the coastline contour (Fig. 1). The grid has square grid boxes of $6334 \mathrm{~m}$. The total number of grid points is 2592 , being 72 points in the direction parallel ( $y$ direction) and 36 points in the direction normal to the coast ( $x$ direction). In the $x$-direction the number of wet points varies between 11 and 15, giving a total of 759 wet points. The bathymetry of the region was created by linear interpolation of the depths registered in bathymetric charts of the Diretoria de Hidrografia e Navegação (DHN). In order to increase the Courant number all the depths exceeding $900 \mathrm{~m}$ were set as being $900 \mathrm{~m}$. The time step utilized in the work was of $45 \mathrm{~s}$, resulting in a Courant number of 0.67 .

\section{Results}

Impulsive uniform wind stress experiments

To characterize seasonal variations of the response of the waters of the NECS the most frequent winter and summer forcing are suddenly applied to the model from the first time step until a quasi steady state is reached.

The wind stress values used in the experiments were estimated from averaged climatological values of wind stress obtained by Hellerman (1967) for $1^{\circ}$ of latitude and $1^{\circ}$ longitude.

The first experiment simulates a typical wind stress for the summer months (December, January and February). A wind stress of $0.042 \mathrm{~Pa}$ parallel to the $y$-axis of the grid and 
of $-0.034 \mathrm{~Pa}$ parallel to $\mathrm{x}$-axis, corresponding to a wind speed of about $6.7 \mathrm{~m} \mathrm{~s}^{-1}$ and $86^{\circ}$ of direction (meteorological angle) is used.

The second experiment simulates the wind stress acting over the region during the winter months (June, July and August). A wind stress of $0.068 \mathrm{~Pa}$ parallel to the $\mathrm{y}$-axis of the grid and of $-0.0078 \mathrm{~Pa}$ parallel to $\mathrm{x}$-axis, corresponding to a wind speed of about $7.5 \mathrm{~m} \mathrm{~s}^{-1} \mathrm{e} 118^{\circ}$ of direction is used.

The experiments simulating summer and winter conditions were performed using both $\mathrm{f}$ and equatorial $\beta$ plane conditions.

Summer, f-plane: During the initial hours the NECS response to the wind is mainly inviscid and is not affected by rotation. Physically it happens because there is no time for the momentum transferred by the wind to the water to cause velocities to increase to a value such that bottom friction becomes an efficient sink of momentum. For times smaller than $\mathrm{f}^{-1}$, rotation can also be neglected.

Then the initial stage of spin-up is characterized by a simple setup-setdown mechanism: setup where the wind blows against the coast and setdown where wind blows away from the coast. The transient fields of sea level displacement and velocity after $6 \mathrm{~h}$ are shown in Figure 2a. The highest rate of change of sea level and velocity fields occurs during the first 24 hours. After that time the Earth's rotation is already controlling the adjustment process. Isolines of sea level displacement and velocity vectors are orienting themselves parallel to the coastline, showing the preference for a geostrophic balance. This tendency of flux parallel to the isobaths can be seen in Figure $2 b$.

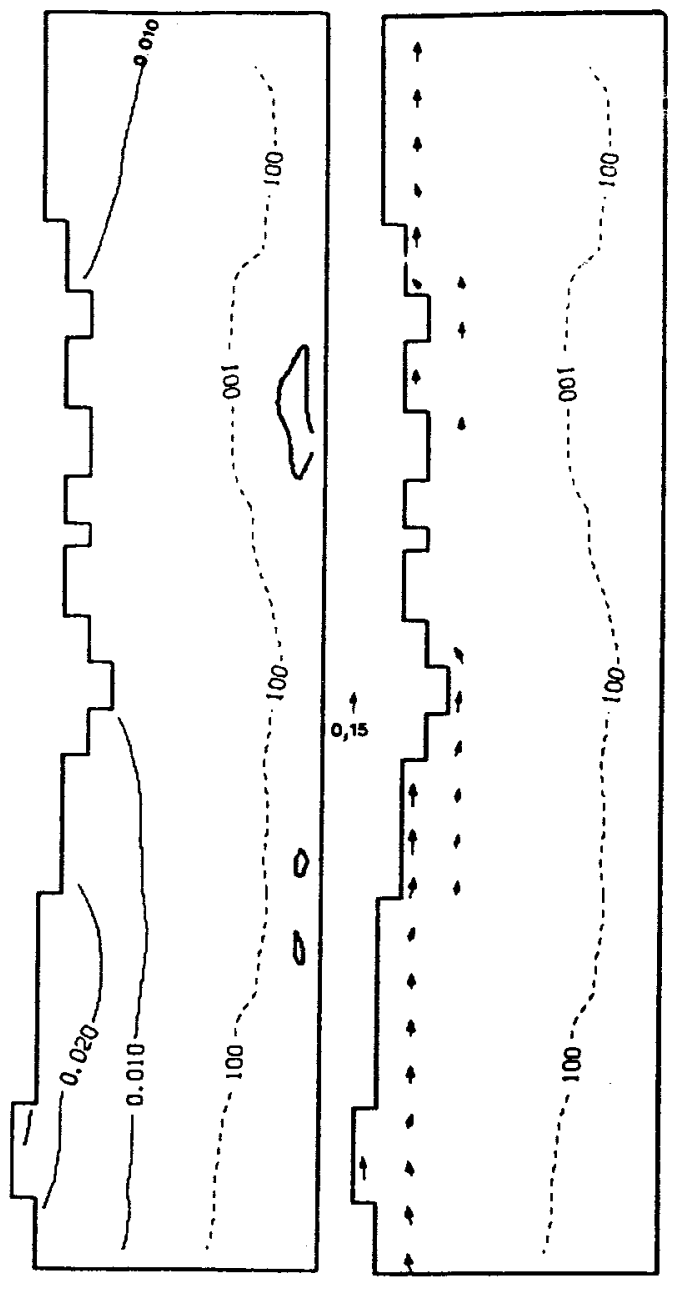

a

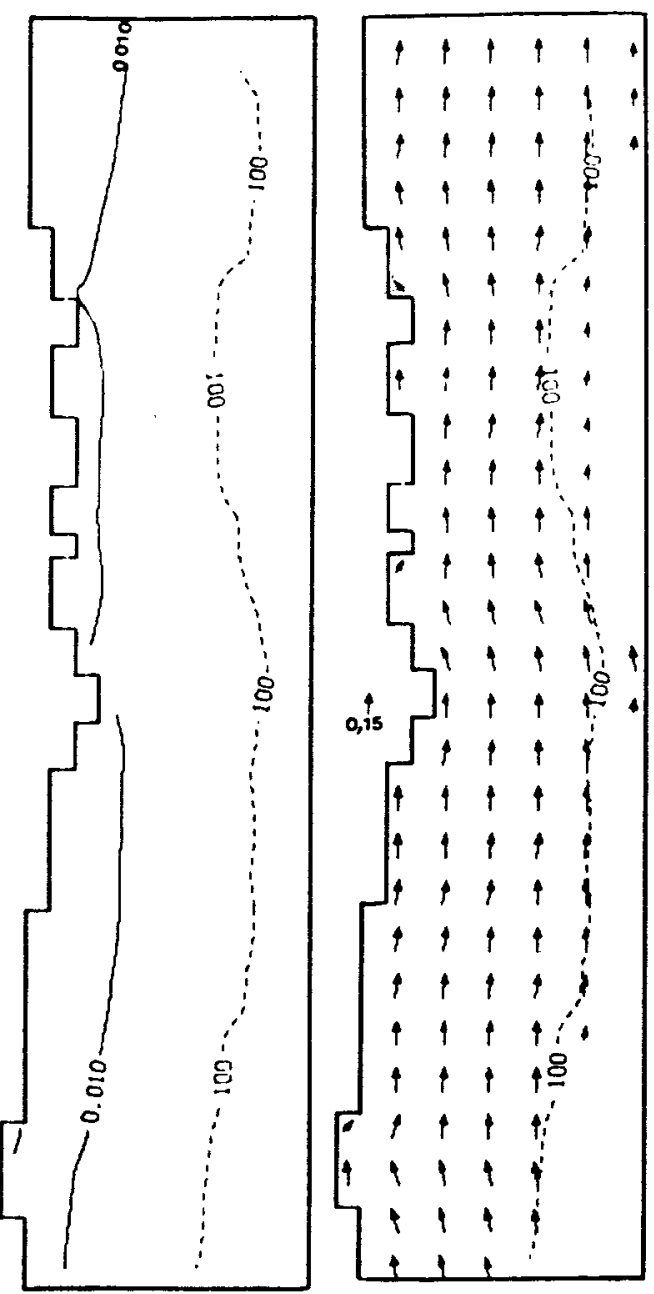

b

Fig. 2. Surface elevation contour ( $m$ ) and velocity vector field $\left(\mathrm{m} \mathrm{s}^{-1}\right)$ maps at (a) $t=6 \mathrm{~h}$ and $(\mathrm{b}) \mathrm{t}=168 \mathrm{~h}$. Each barb of the velocity vector adds $0.15 \mathrm{~m} \mathrm{~s}^{-1}$. f-plane domain. Summer experiment. 
The time history of terms in the $\mathrm{x}$ and $\mathrm{y}$ momentum balances was performed for three different sections normal to the coast; each cross-shelf line displaying information about three points: nearshore point, mid-shelf point and shelf-break point. Here, the results obtained in only one cross-shelf section (in the middle of the region) is shown because the differences among the sections are not significant.

Near the coast, the $x$-momentum balance occurs mainly between the wind stress and the pressure gradient with a smaller contribution from the Coriolis force (Fig. 3a). Analytical solutions obtained for a straight coast with a wind blowing against the coast (Csanady, 1974) show that when the steady state is reached there is a pilling up of water near the coast and the velocity components parallel to the coast are zero. These zero velocities are due to the very small values of the velocities normal to the coast which prevent Coriolis force of accelerating the flux in the direction parallel to the coast.

The y-momentum balance, for the same point (Fig. 3b), reveals that the role of balancing the wind stress, represented mainly by the local acceleration of the velocity during the initial stages of the spin up process, is progressively taken over by the bottom friction. Currents increase to a point where bottom stress starts to be very effective in dissipating momentum, consequently blocking the local acceleration of the fluid. Near the coast, because of the smaller depths, the bottom stress becomes rapidly an important sink of the momentum transferred from wind to water.

The momentum balance for a mid-shelf point (Fig. 3c,d) shows the presence of geostrophic balance induced by the wind component parallel to the coast. The cross-shelf wind stress is balanced by the pressure gradient normal to the coast. The y-momentum balance (Fig. 3d) shows that after an initial period when the local acceleration is important, the main balance occurs between the wind stress and the bottom friction.

Near the continental slope, the basic $x$-momentum balance is geostrophic with an important contribution of both wind stress and advective terms (Fig. 3e). The importance of the advective terms in the balance is due to the steep variations of depth existent in the direction normal to the coast near the shelf break. In the y-direction the balance remains controlled by the bottom stress after the quasi steady state is reached (Fig. 3f).

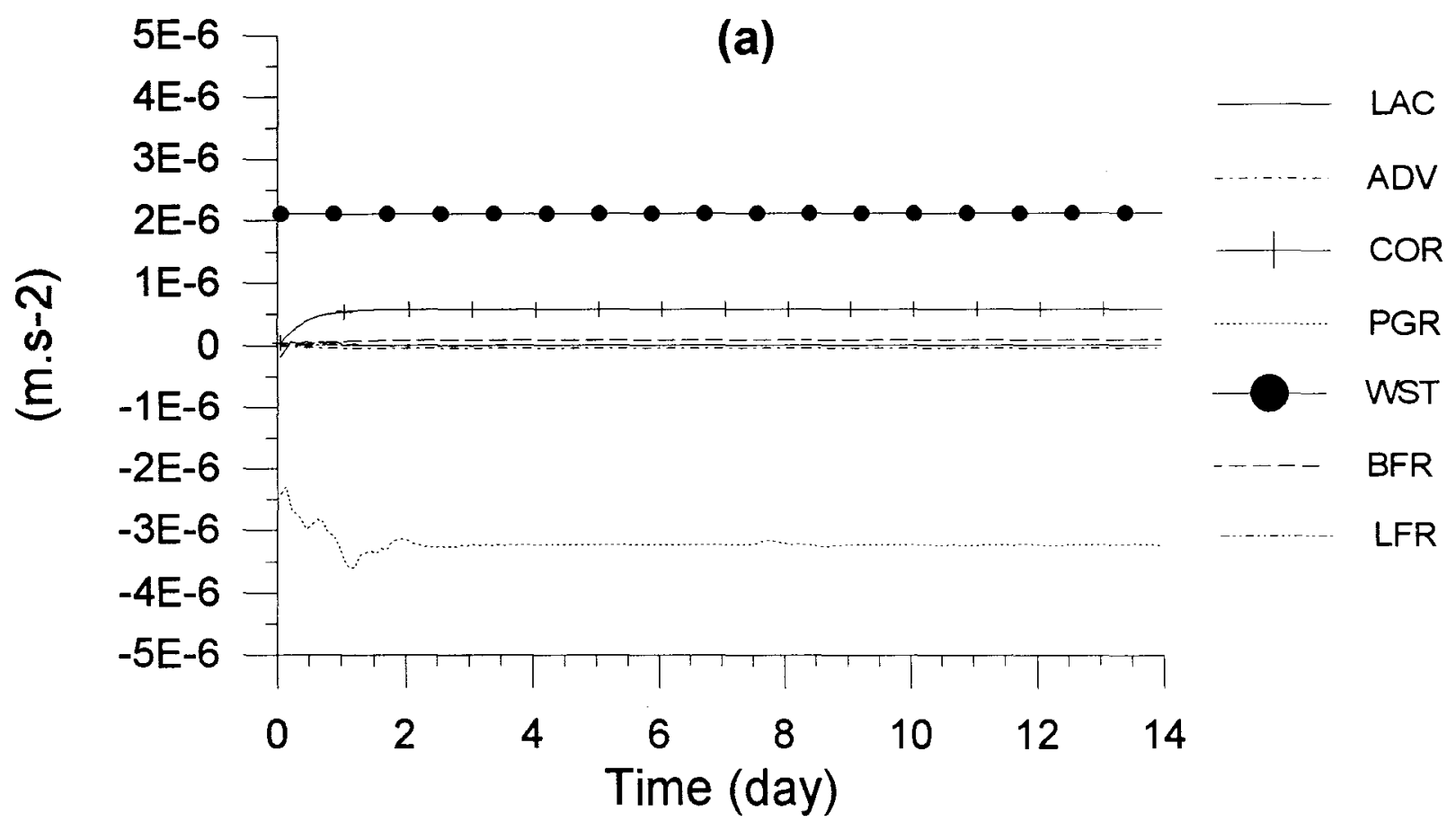

Fig. 3. Time history of terms in the momentum balance at selected points of the domain. Nearshore point: (a) $x$-direction and (b) $y$-direction. Mid-shelf point: (c) $x$-direction and (d) $y$ direction. Shelf-break point (e) $x$-direction and (f) $y$-direction. LAC: local aceleration; ADV: advection; COR: Coriolis; PGR: gradient pressure; WST: wind stress; BFR: bottom friction; LFR: lateral friction. f-plane domain. Summer experiment. 

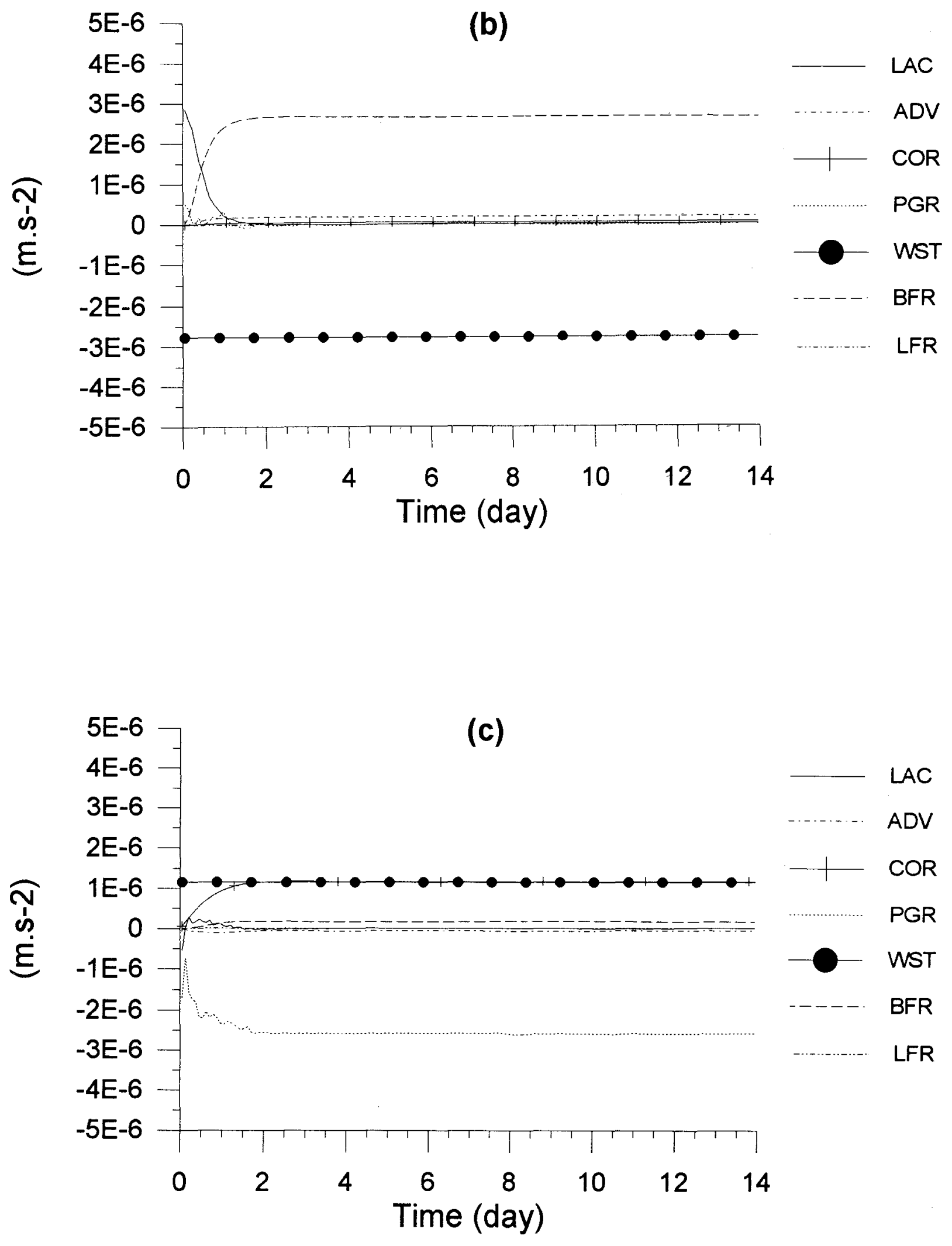

Fig. 3. Cont. 


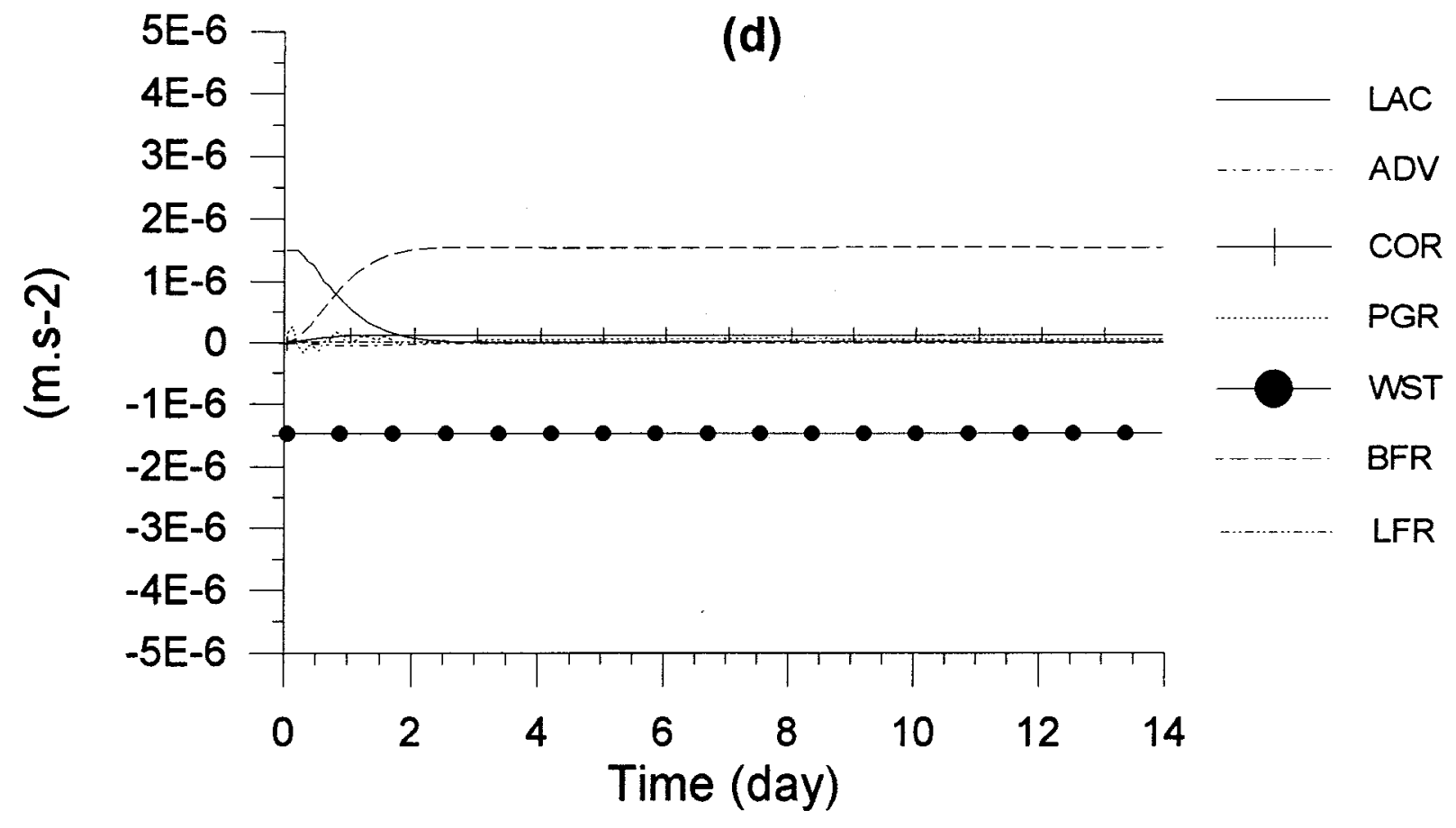

(e)

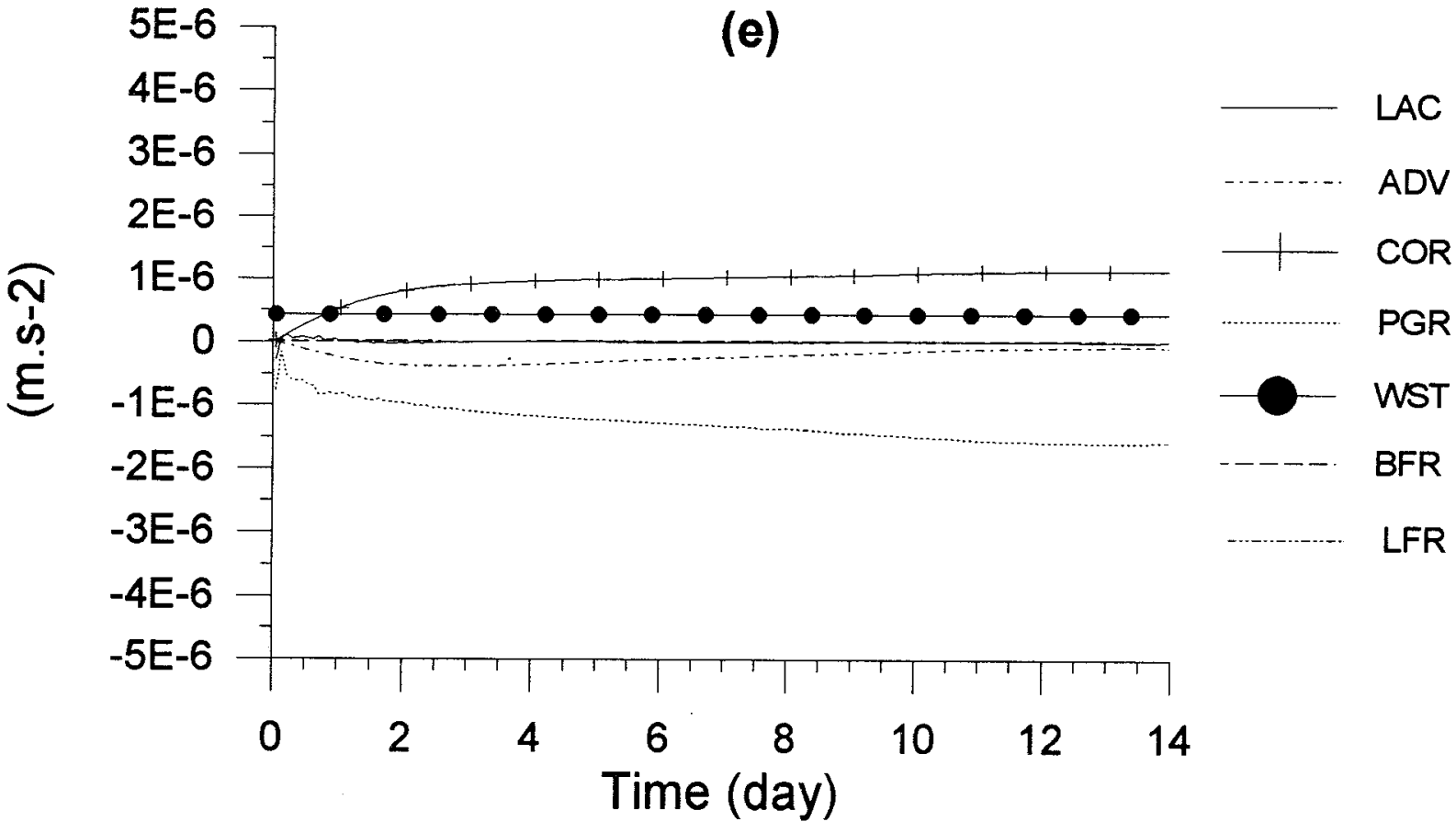

Fig. 3. Cont. 
Time evolution of sea level and velocity components for the same points of Figure 3 are shown in Figure 4.

Sea level time history (Fig. 4a) shows that the sea level elevation decreases in direction to the outer-shelf. When the steady state is reached the sea level elevation has a constant value in time of order of $1-2 \mathrm{~cm}$. This pile up of water in the coastal region is in agreement with theoretical results (Csanady, 1982).

The velocity component normal to the coast (u) presents values very small (Fig. $4 \mathrm{~b}$ ) but not zero as would be expected from simple theoretical models. The velocities are not zero for two main reasons. First, the existence of topographic variation in the direction parallel to the coast. Second, the coastline is not straight and therefore pressure gradients can be generated along the coast. Both processes may induce the appearance of motions normal to the coast.

The time evolution of the alongshelf velocity ( $v$ ) shows that after the steady state is reached $v$ tends to constant values varying between 3 and $14 \mathrm{~cm} / \mathrm{s}$. The near coast point presents the highest velocity (Fig. 4c).

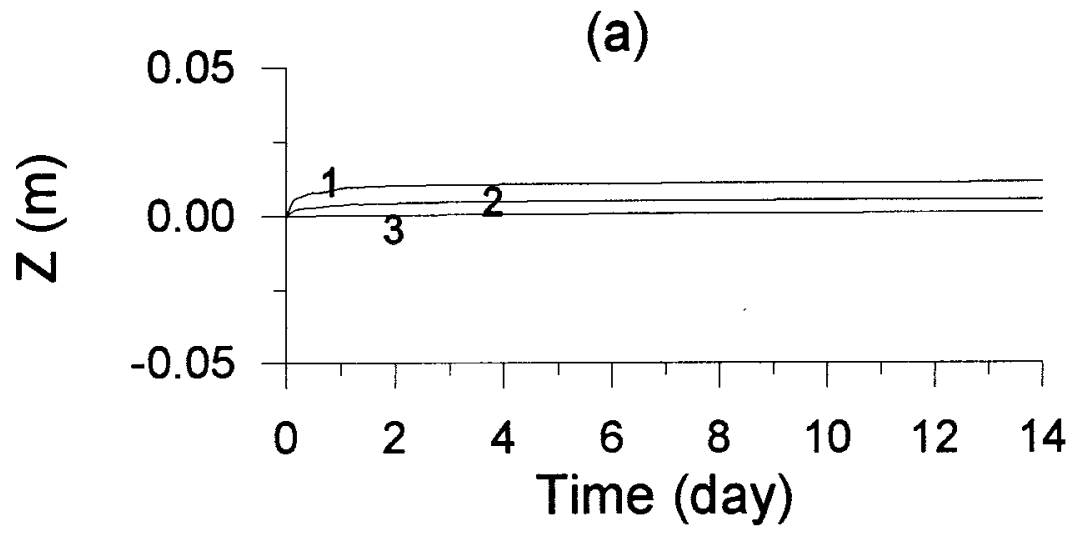

(b)
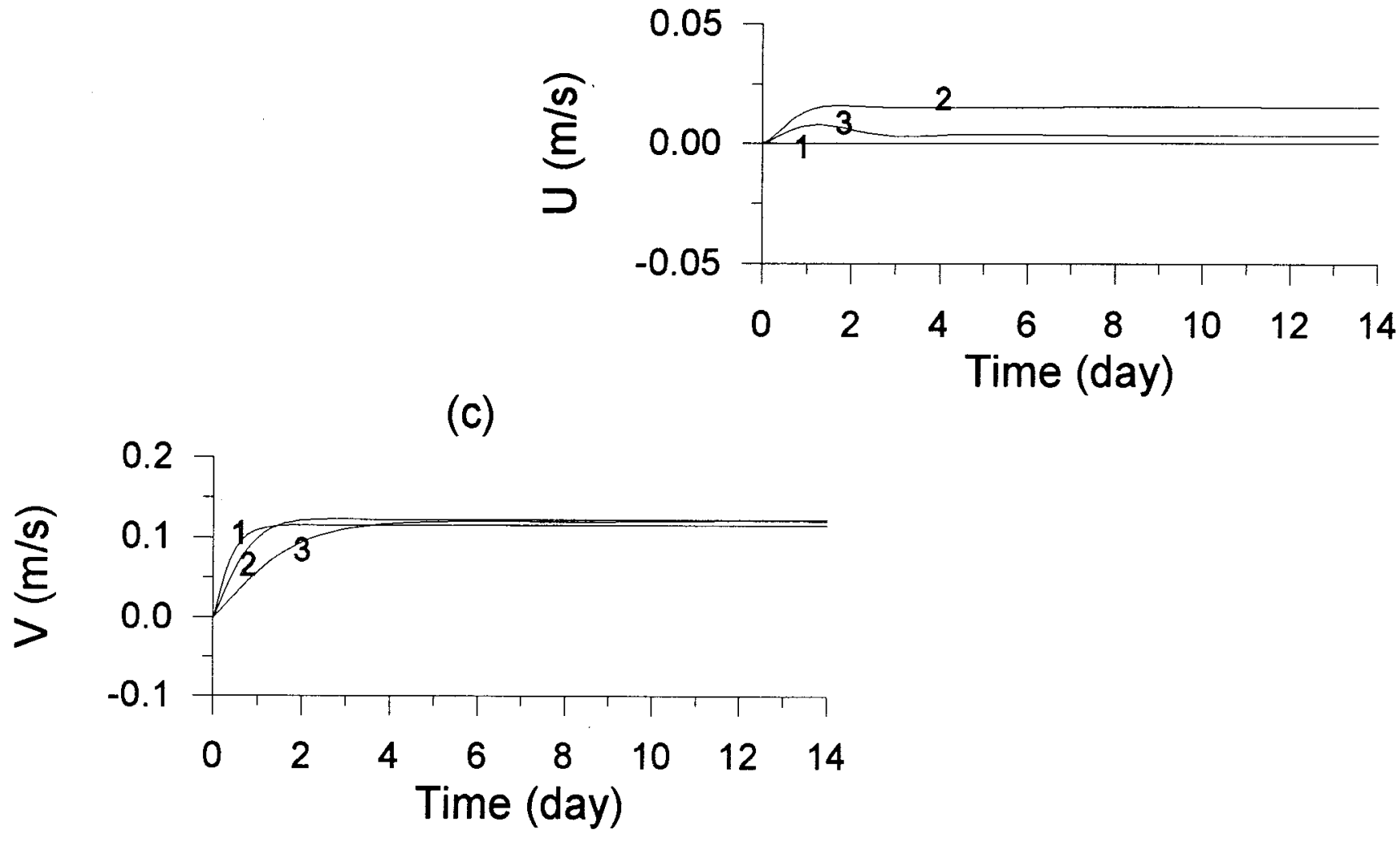

Fig. 4. Time history of (a) surface elevation, (b) cross-shelf velocity component and (c) alongshelf velocity component at three points of the cross-shelf section. Nearshore point (number 1); near mid-shelf point (number 2) and shelf-break point (number 3). f-plane domain. Summer experiment. 
Figures 2 and 4 show that both current and sea level fields are confined to the continental shelf region and that these fields tend to be null as the distance to the coast increases.

Winter, f-plane: The results of this section are similar to the previous one. Now, however, the wind component parallel to the coast is one order larger than the cross-shelf wind component and therefore there is a dominance of phenomenon associated to the $y$-component of the wind stress.

The x-momentum balance for the nearshore point (Fig. 5a) can be divided in two parts: one part geostrophic, related to the alongshore wind component and other part induced by the normal component of the wind resulting a balance between the pressure gradient and the wind stress. The y-momentum balance (Fig. 5b), similarly to the summer experiment, is controlled mainly by the bottom stress.

Near the shelf-break a true steady state is never reached (Fig. 5e). The pressure gradient presents a time pulsation during the whole experiment. In the $\mathrm{x}$-direction the basic momentum balance is still geostrophic but there is also a contribution of the advective terms because of the topography.

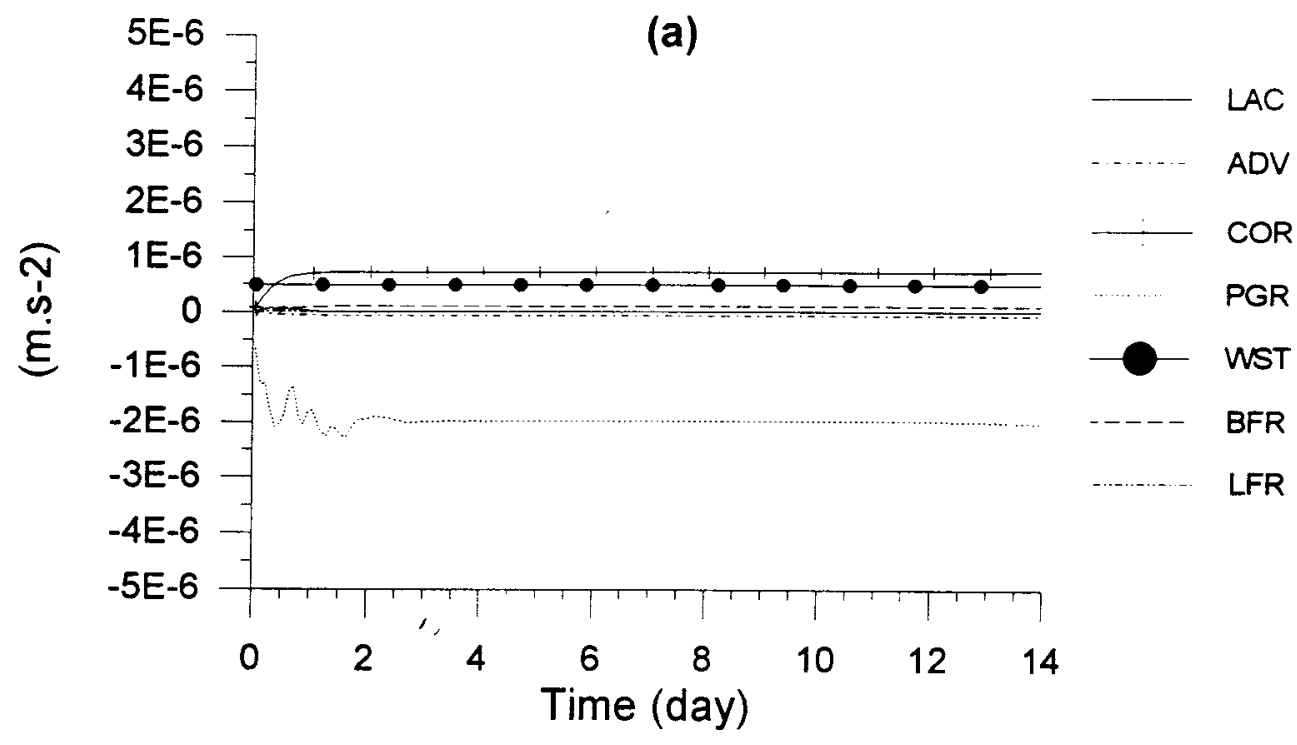

(b)

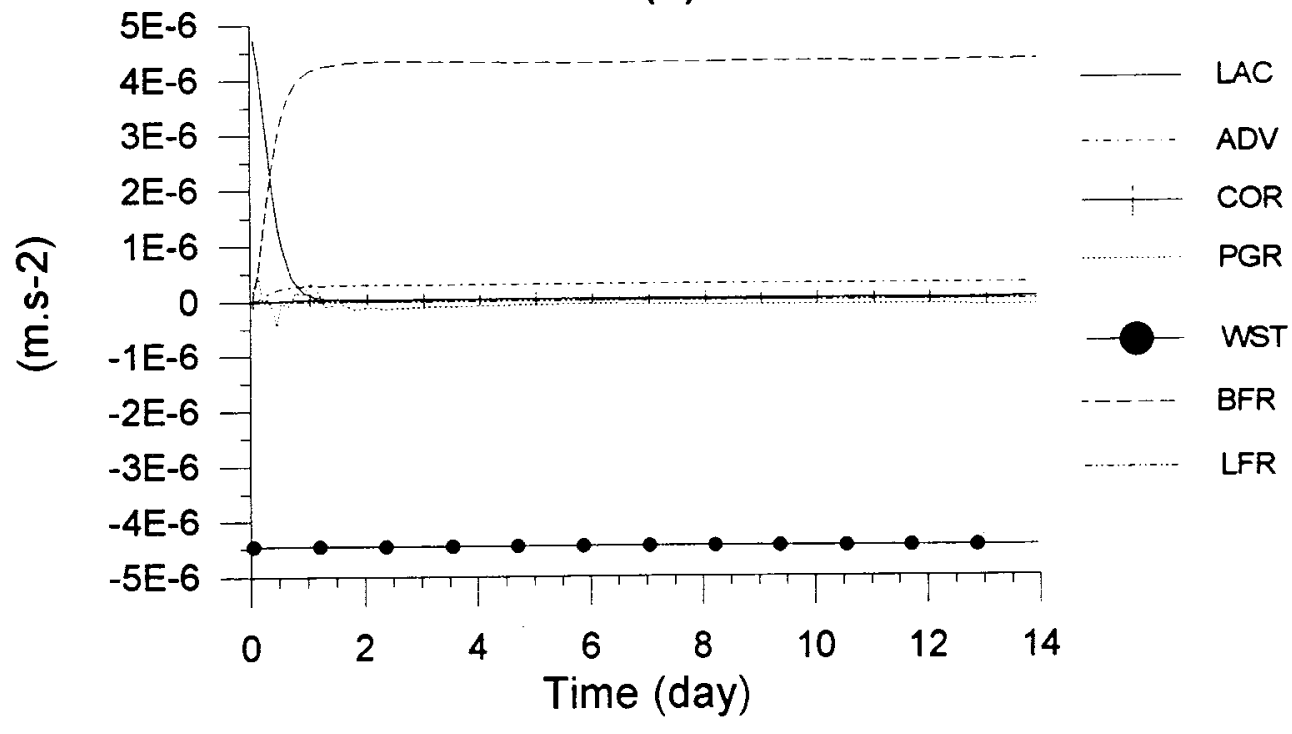

Fig. 5. Time history of terms in the momentum balance at selected points of the domain. Nearshore point: (a) $x$-direction and (b) y-direction. Mid-shelf point: (c) $x$-direction and (d) y-direction. Shelf-break point: (e) $x$-direction and (f) $y$-direction. LAC: local aceleration; ADV: advection; COR: Coriolis; PGR: pressure gradient; WST: wind stress; BFR: bottom friction; LFR: lateral friction. f plane domain. Winter experiment. 

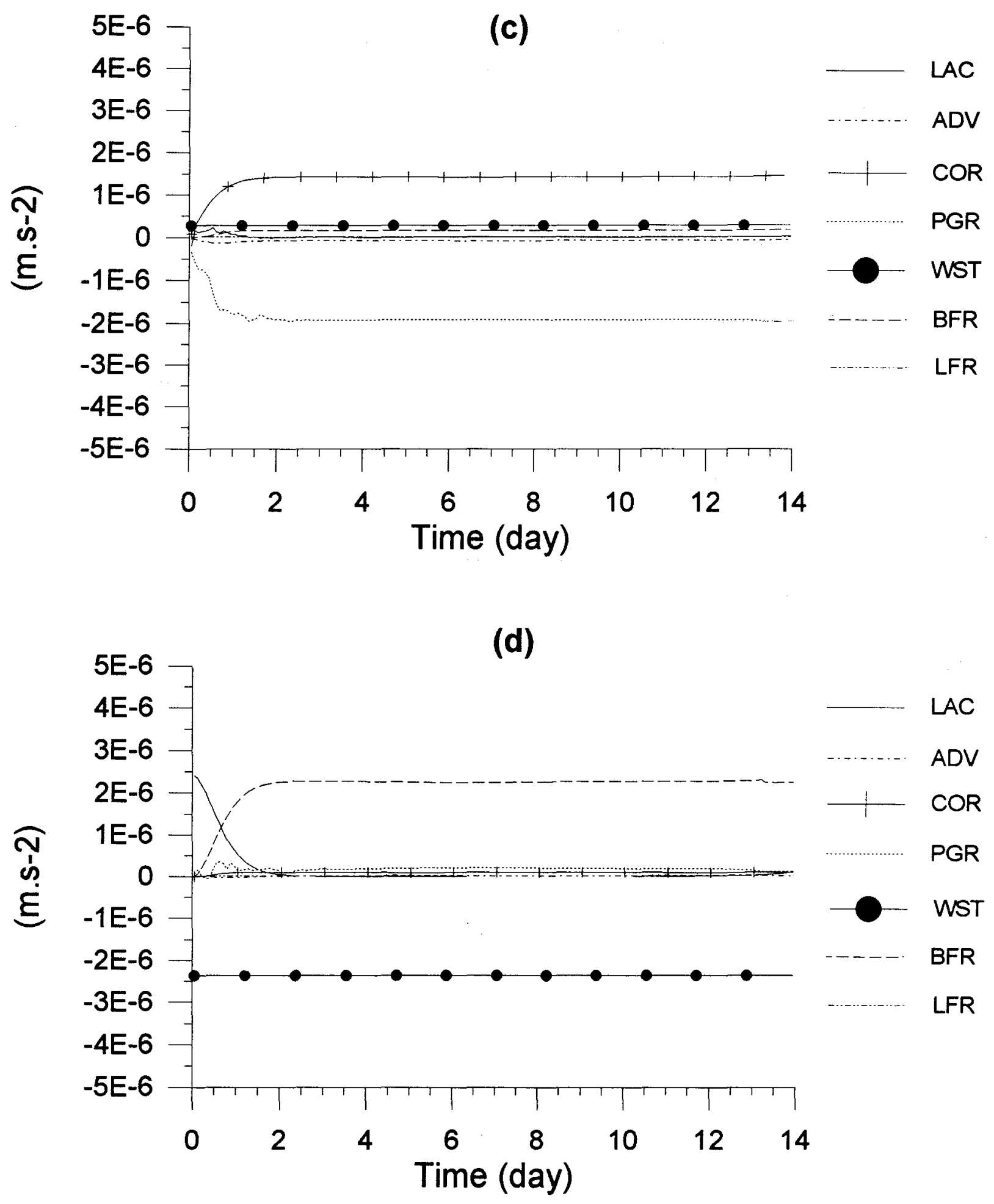

Fig. 5. Cont. 

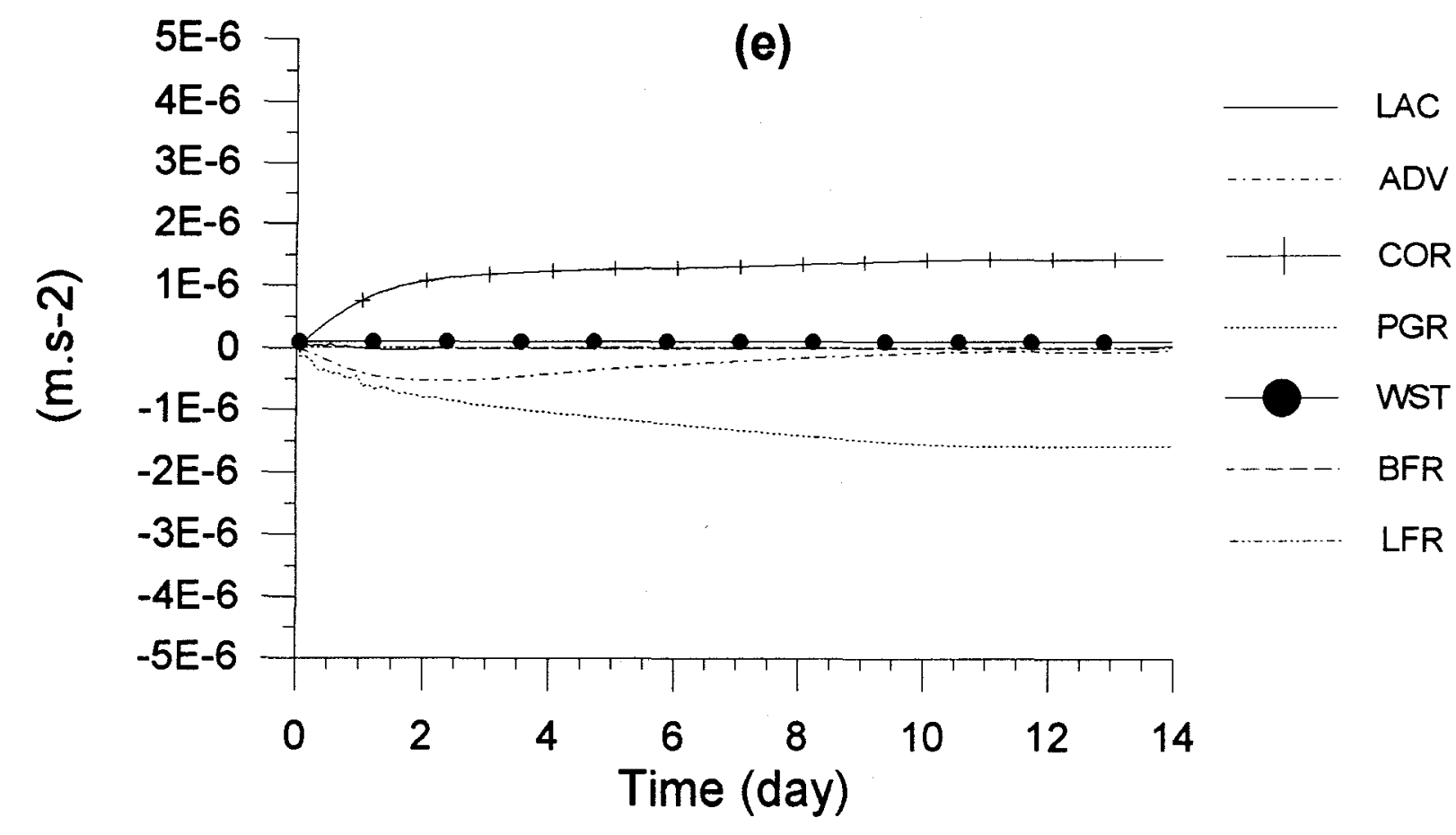

-1 COR PGR

WST

-..- BFR

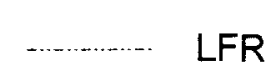

(f)

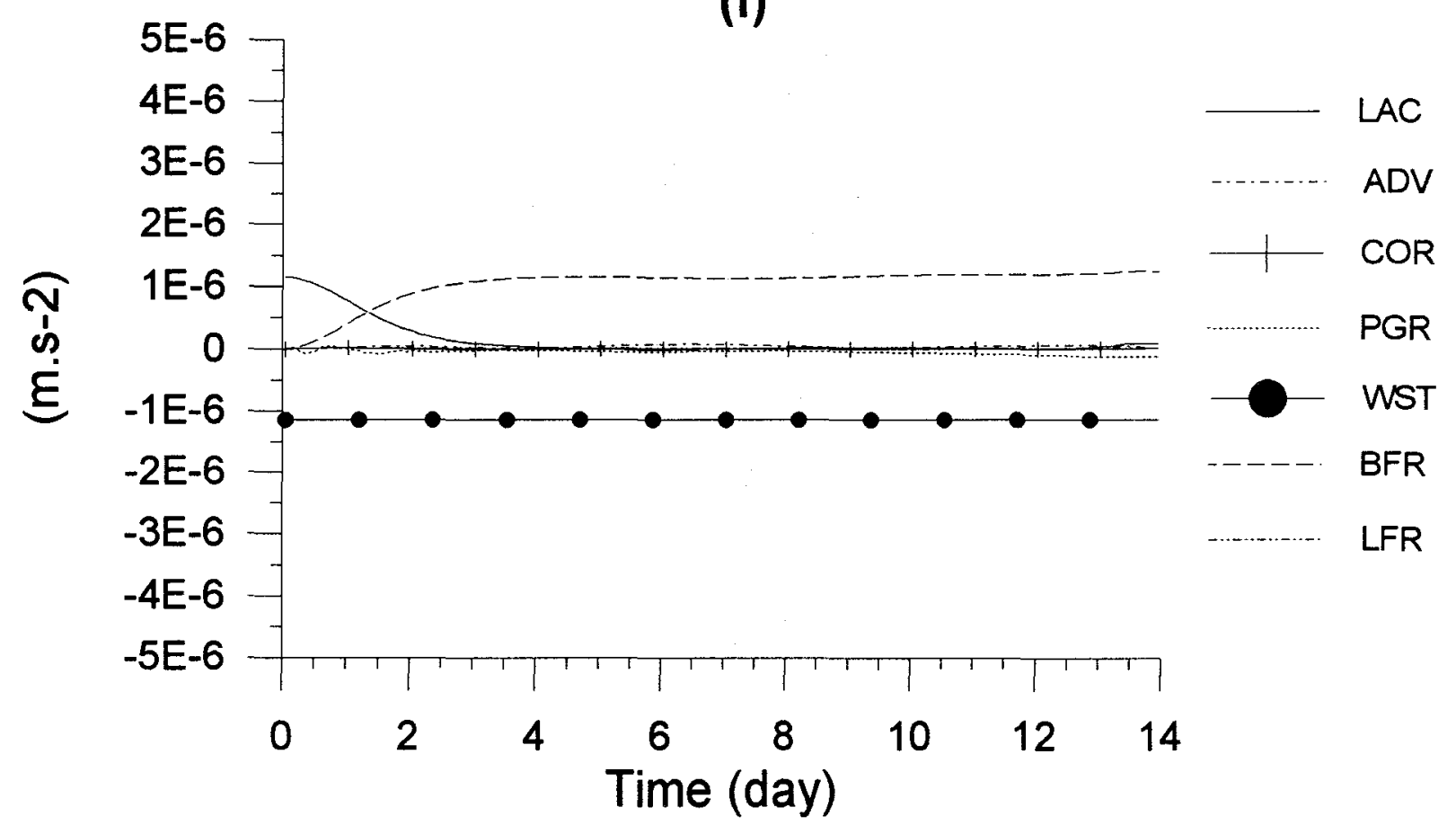

Fig. 5. Cont. 
During the first 24 hours of numerical integration the sea level field is disorganized and almost null (Fig. 6a). After that time the flux tends to be parallel to the isobaths. The velocity field, obtained in this experiment (Fig. 6b), is stronger than that observed in the summer experiment (Fig. 2b). It occurs because the alongshelf wind component is more intense in the winter.
The time evolution of the sea level and velocity (not shown) are similar to those obtained in the previous experiment. The wind component normal to the coast, however, is less intense during the winter than during the summer which results in smaller near- shore sea level values.
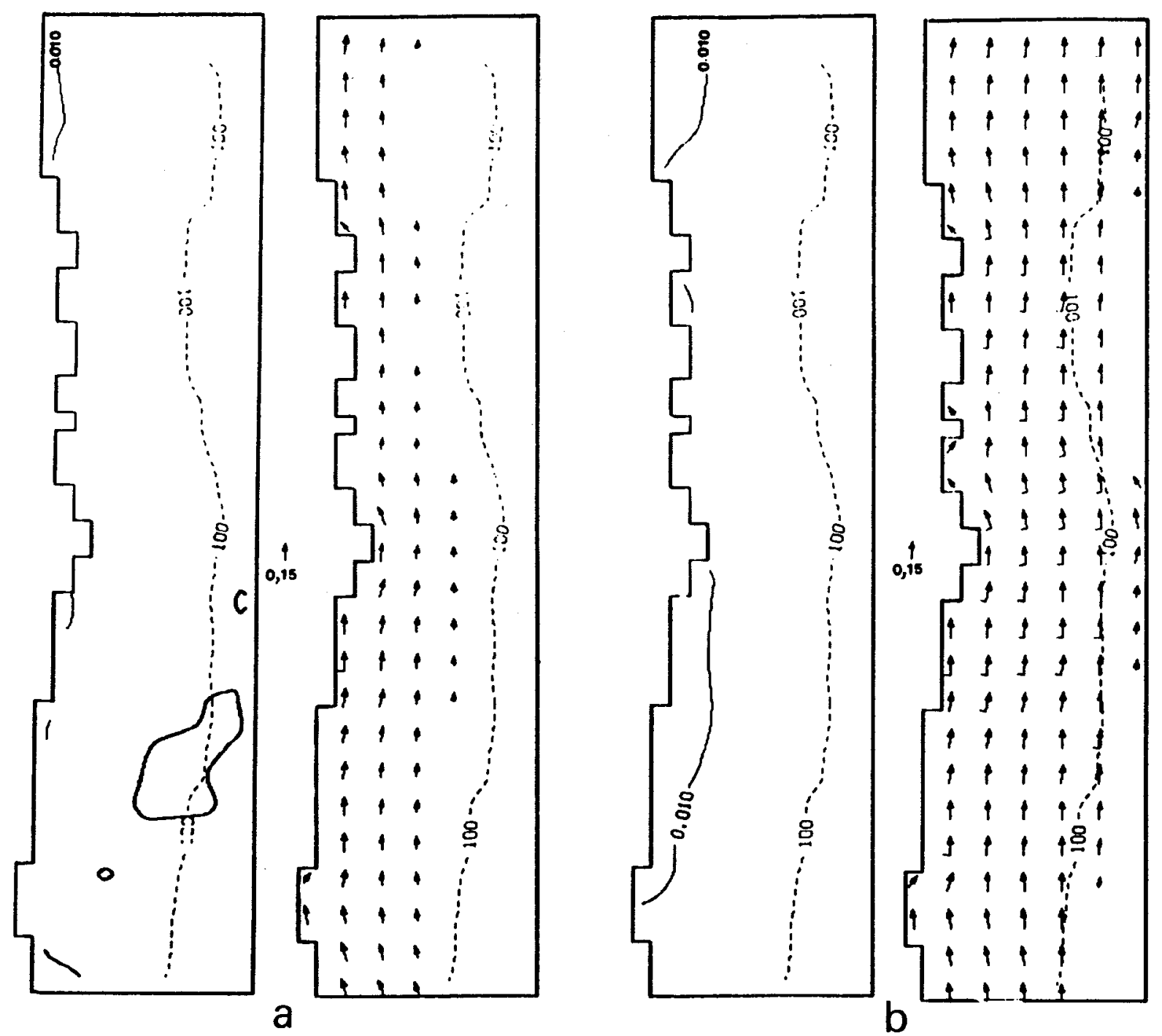

Fig. 6. Time history of (a) surface elevation, (b) cross-shelf velocity component and (c) alongshelf velocity component at three points of the cross-shelf section. Nearshore point (number 1); mid-shelf point (number 2) and break-point (number 3). f plane domain. Winter experiment. 
The sea level values obtained in all experiments are very small (Figs. 2, 4 and 6). This occurs due to the low latitude of the studied region. Figure 7 shows the results of an additional experiment made using the model considering a constant depth $(\mathrm{H}=60 \mathrm{~m})$ and a regular grid $(20 \times 24)$. The winter wind stress was used as forcing for the experiments. The experiment was run using two different values of the Coriolis parameter. According to this figure, near the coast, the values of sea level are of the order of 20 $\mathrm{cm}$ (Fig. 7a) when the value of $\mathrm{f}$ is $-6.410^{-5} \mathrm{~s}^{-1}$ (typical value of middle latitudes) and the near coast sea level is of the order of $3 \mathrm{~cm}$ (Fig. $7 \mathrm{~b}$ ) when the Coriolis parameter is -9.7 $10^{-6} \mathrm{~s}^{-1}$ (value of the studied region). It confirms the importance of the Coriolis parameter in the generation, by geostrophic adjustment, of the elevation/depression of the sea level.

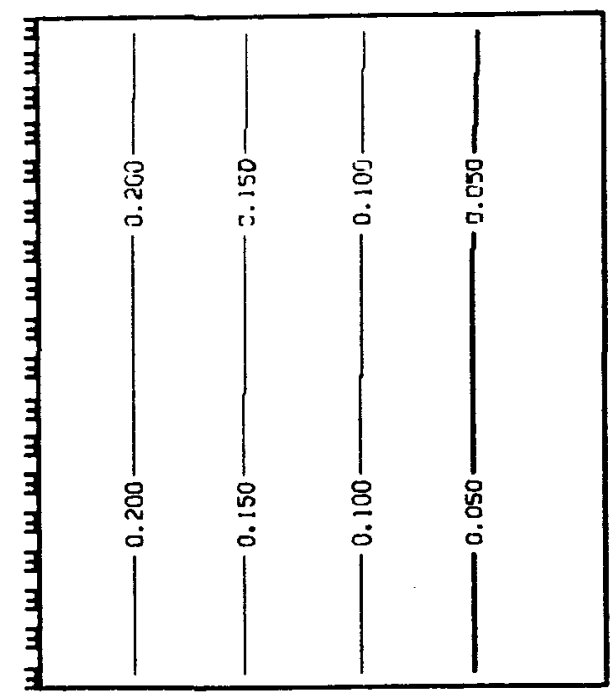

a

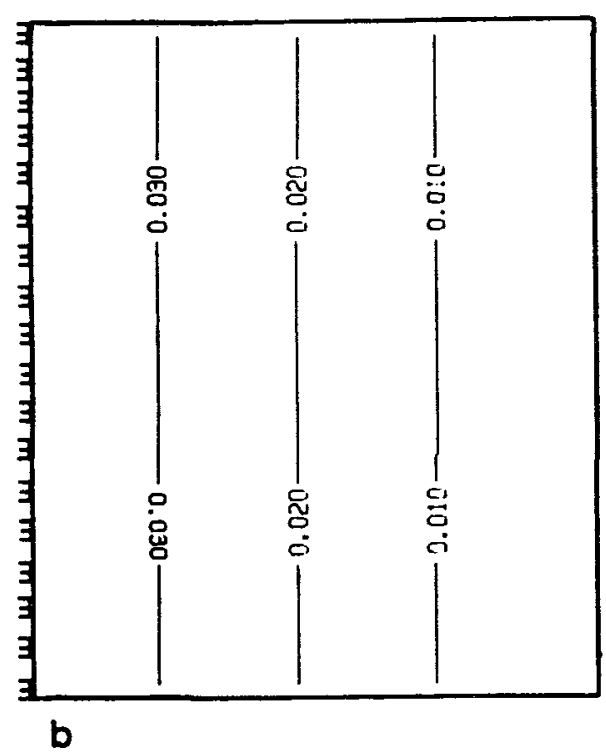

Fig. 7. Surface elevation contour map (meters) for (a) mid- latitude region and (b) low-latitude region.
Figures 2, 4 and 6 show that the continental shelf waters response to the wind stress forcing is much more intense than the response of the slope waters. The sea level and currents - largest near the coast - tend to zero as the distance from the coast becomes of the order of the width of the continental shelf. Thus, the dynamics of the continental slope, totally artificial because of the non inclusion of the North Brazil Current, is expected not to influence the results of the region of interest: the continental shelf.

Summer and winter, Equatorial $\beta$-plane: To analyze possible differences between the model response using a f-plane and an equatorial $\beta$-plane approximation the experiments simulating the summer and winter conditions were again performed considering the model described in section 3 in an equatorial $\beta$-plane domain. In this approximation the effects of spherecity of the Earth are retained by approximating $f$ with a linear function of the latitudinal coordinate which is measured positive northward from the equator. The other model variables and the initial and boundary conditions remained the same as used previously.

The results obtained in this experiment are very similar to those previously described. Figures 8 and 9 show both sea level elevation and velocity fields for the summer and winter experiments, respectively, after 7 days of numerical integration. These figures are very similar to figures $2 b$ (summer) and $6 b$ (winter). The similarity of the results occurs because the Coriolis effect remains of the same order $\left(10^{-5} \mathrm{~s}^{-1}\right)$ in both experiments. Because of the small value of the Coriolis parameter for the region, the topographic effect is always one order larger than the $\beta$ effect as can be seen by the following ratio (Pedlosky, 1979):

$$
\frac{\beta \text { effect }}{\text { topografic effect }}=O\left[\frac{\beta_{0} \mathrm{~L} / \mathrm{f}}{\Delta \mathrm{H}_{0} / \mathrm{H}_{0}}\right]
$$

where $L$ is the distance parallel to the coastline, $\Delta H_{0}$ is the depth variation at the direction normal to the coastline and $\mathrm{H}_{0}$ is the local depth.

Using typical values for the studied region, $\mathrm{L}=\mathrm{O}$ $\left(10^{6} \mathrm{~m}\right), \mathrm{f}=\mathrm{O}\left(10^{-5} \mathrm{~s}^{-1}\right), \beta_{\mathrm{o}}=\mathrm{O}\left(10^{-11} \mathrm{~m}^{-1}\right)$ and $\Delta \mathrm{H}_{0} / \mathrm{H}_{0}=$ $O(1)$, the above ratio shows that the change of planetary vorticity with the latitude is less important than the change of vorticity induced by topographic variations. 

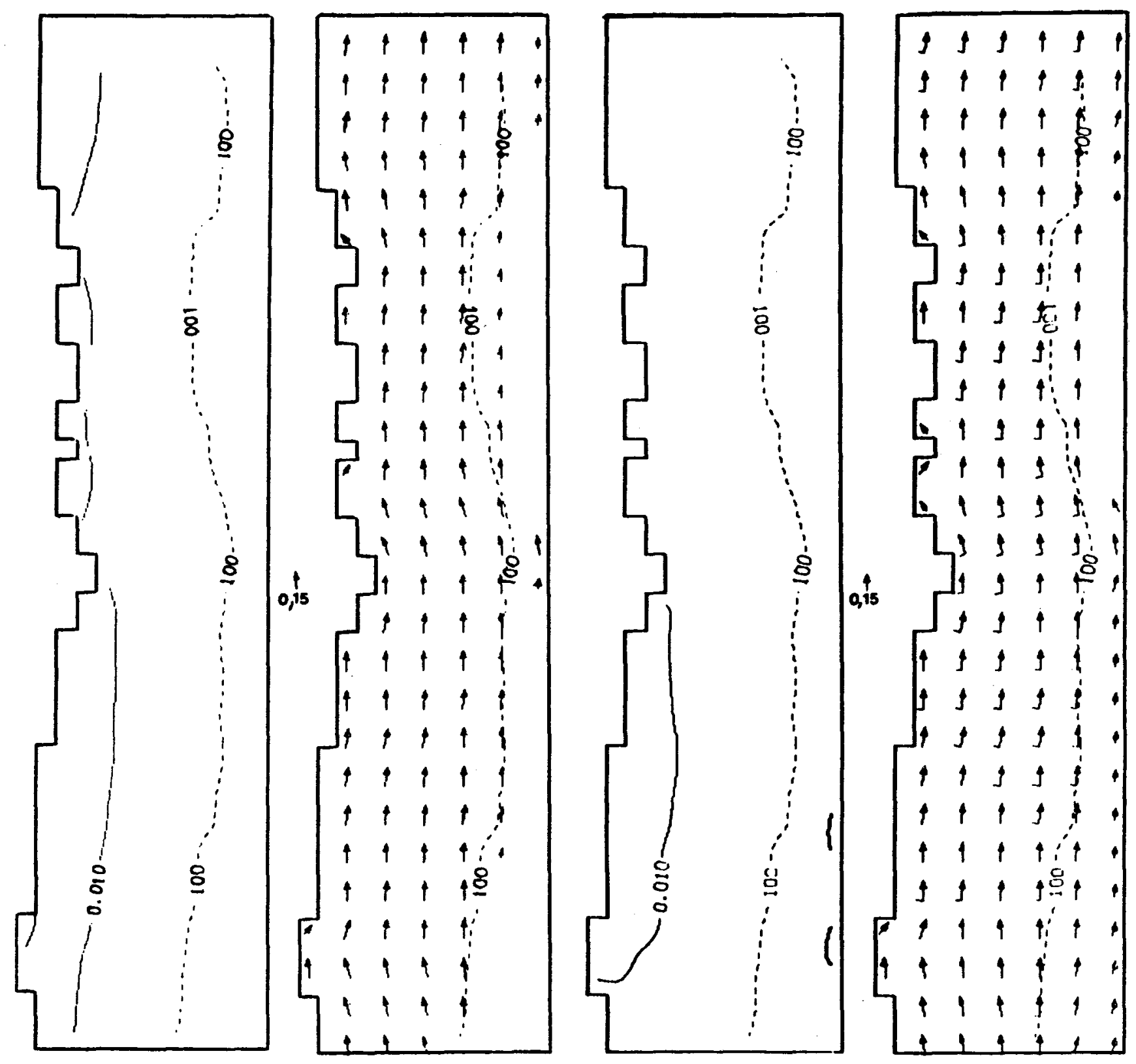

Fig. 8. Surface elevation contour $(m)$ and velocity vector field $\left(\mathrm{m} \mathrm{s}^{-1}\right)$ maps after 7 days of numerical integration. Each barb of the velocity vector adds $0.15 \mathrm{~m} \mathrm{~s}^{-1}$. Equatorial $\beta$-plane domain. Summer experiment.

Fig. 9. Surface elevation contour $(\mathrm{m})$ and velocity vector field $\left(\mathrm{m} \mathrm{s}^{-1}\right)$ maps after 7 days of numerical integration. Each barb of the velocity vector adds $0.15 \mathrm{~m} \mathrm{~s}^{-1}$. Equatorial $\beta$-plane domain. Winter experiment. 


\section{Transient wind stress experiment}

Transient shelf water response was investigated using surface winds from the Fortaleza airport, during the period extending from $14 / 03$ to $25 / 03 / 79$. Model results were compared to current data collected at $40 \mathrm{~km}$ from the coast $\left(03^{\circ} 06^{\prime} \mathrm{S}, 038^{\circ} 49.5^{\prime} \mathrm{W}\right)$ during the same time period.

The wind data, obtaincd over the continent ( $\left.U_{\text {continent }}\right)$, was correct in order to be extrapolated for the ocean (Ucean) using Hsu (1986) model: $U_{\text {oceano }}=1.62+1.17$ $\mathrm{U}_{\text {continent. }}$
The wind field was assumed to be spatially homogeneous and its time variation was considered hourly.

Figure 10 shows the time series of the components parallel to the coast of the wind (Fig. 10a), modeled current (Fig. 10b) and low-pass observed current (Fig. 10c). According to this figure the modeled current is able to roughly describe observed current pattern but its intensity is weaker than that of observed current.

In the direction normal to the coast, the intensity of both wind and current (Fig. 11) are weaker than the alongshore
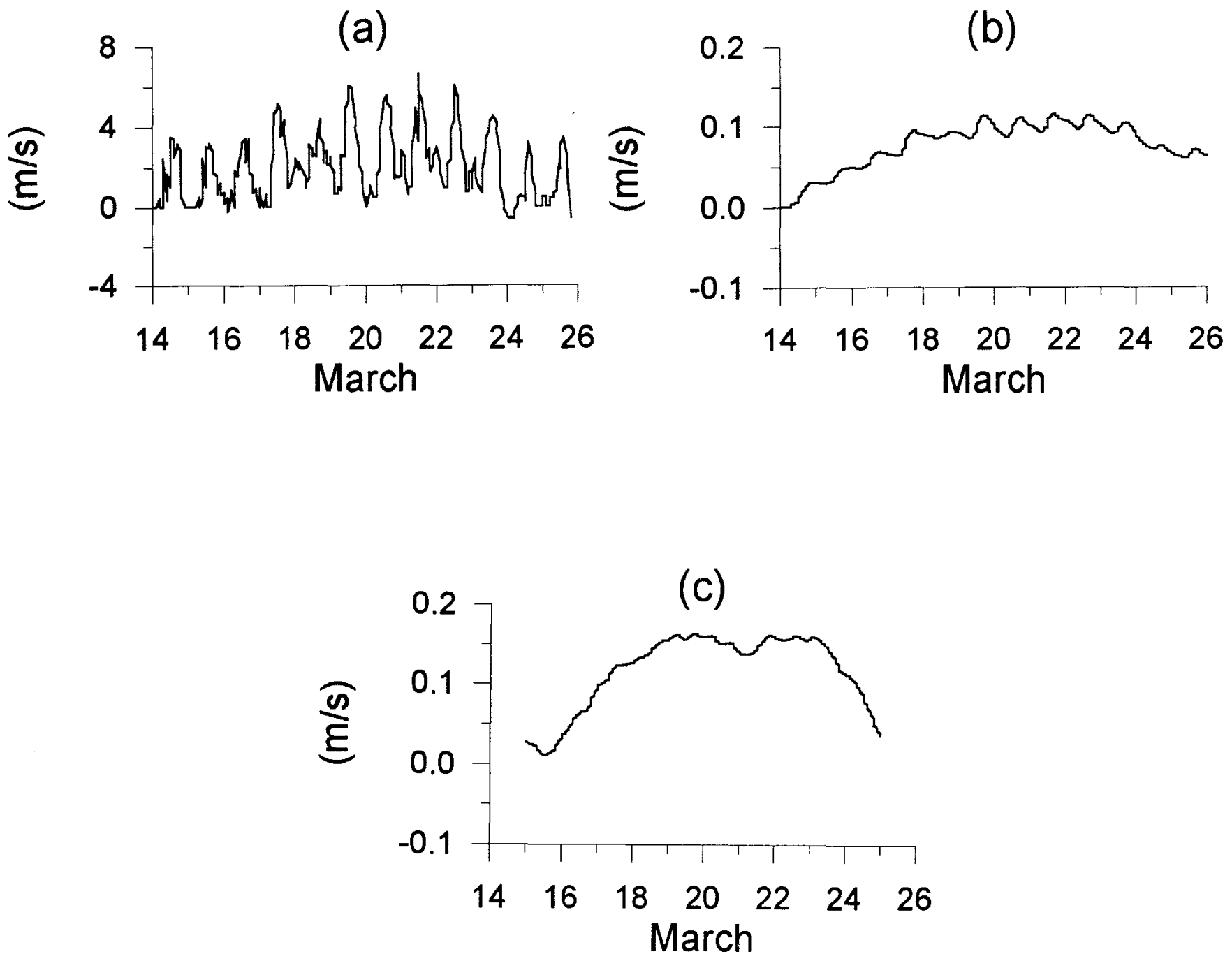

Fig. 10. Time history of alongshelf components of (a) observed wind, (b) modeled current and (c) observed current. 
component indicating the predominance during the experiment of phenomenon related to the wind component parallel to the coast.

The modeled current fields for days $16,19,22$ and 25 of March, at $8 \mathrm{~h}$, are shown in Figure 12. During the whole experiment the flux is practically parallel to the isobaths and the current intensity reaches a maximum at day 22 (Fig. 12c). This result is in agreement with the wind and current fields observed in the region.

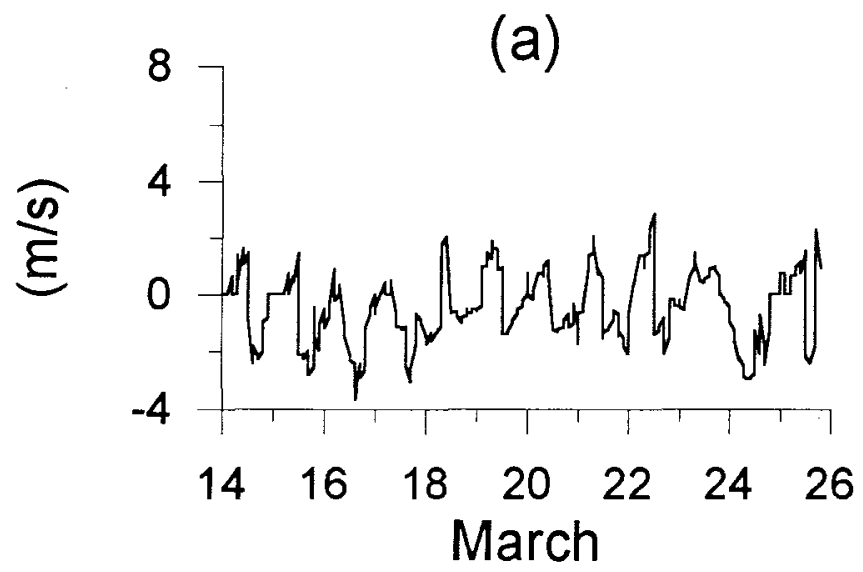

The difference between the modeled and the observed current may occur due to several factors, as discussed below.

The wind used to force the numerical model, despite being corrected using Hsu (1986) model, could have been underestimated, generating currents also underestimated.

The hypothesis of spatially homogeneous wind, used in the experiment, has certainly contributed to reduce the correlation between modeled and observed currents.
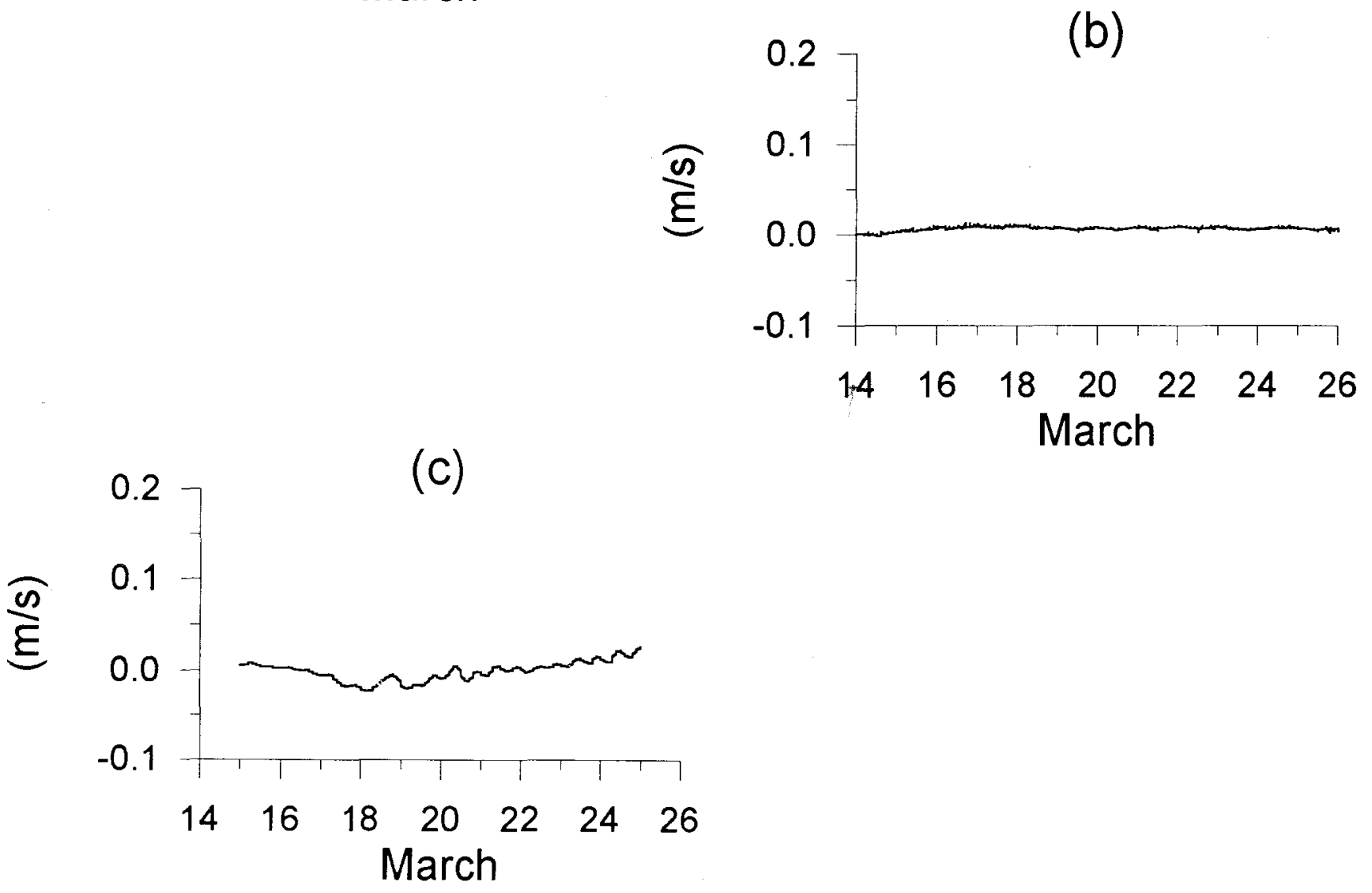

Fig. 11. Time history of cross-shelf components of (a) observed wind, (b) modeled current and (c) observed current. 


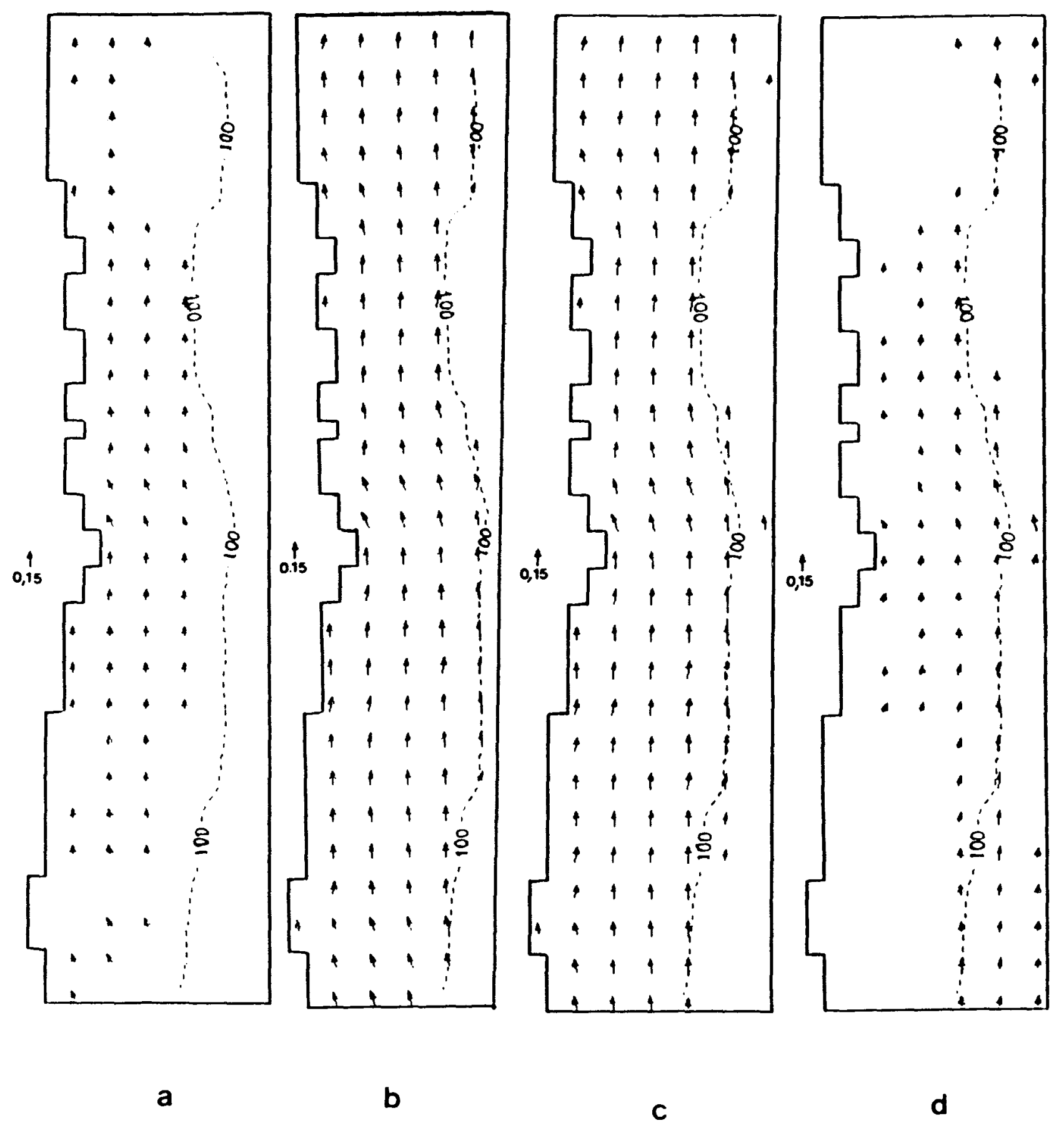

Fig. 12. Surface elevation contour (m) and velocity vector field $\left(m s^{-1}\right)$ at days (a) 16, (b) 19, (c) 22 and (d) 25 of March of 1979. Each barb of the velocity vector adds $0.15 \mathrm{~m} \mathrm{~s}^{-1}$. 
The position of the observed currents, very near the shelf-break, could be under the influence of the North Brazil Coastal Current. This current, not included in the model, flowing to northwest with velocities higher than 20 $\mathrm{cm} / \mathrm{s}$ could intensify the current observed in the region.

The alongshore dimension of the modeled region is not large enough to solve continental shelf waves. These waves, with equatorward propagation, could also affect the circulation in the model domain.

\section{Acknowledgements}

J. Soares wishes to thanks FAPESP, CAPES and CNPq for the finantial support through a scholarship. B.M. Castro Filho was partially supported by grant $303877 / 86-3$ from CNPq/Brazil.

\section{References}

Castro Filho, B. M. 1985. Subtidal response to wind forcing in the South Brazil Bight during winter. Ph.D. Thesis. University of Miami, RSMAS. 211p.

Csanady, G. T. 1974. Barotropic currents over the continental shelf. J. phys. Oceanogr., 4: 357-371.

Csanady, G. T. 1982. Circulation in the coastal ocean. London, D. Reidel. 279p.

DHN. 1968. 30 Comissão Oceanográfica "Operação Norte/Nordeste I". Diretoria de Hidrografia e Navegação da Marinha do Brasil.

Foreman, M. G. G. 1984: A two-dimensional dispersion analysis of selected methods for solving the linearized shallow water equations. J. comp. Phys., 56:287-323.
Gill, A.E. 1982. At mosphere-ocean dynamics. San Diego, California, Academic Press. 645p.

Hellerman, S. 1967. An update estimative of the wind stress on the world ocean. Mon. Weath. Rev., 95: 607-626.

Henry, R. F. 1981. Richardson-Sielecki schemes for shallow-water equations, with applications to Kelvin waves. J. comp. Phys., 41:389-406.

Hsu, S. A. 1986: Correction of land-based wind data for offshore applications: A further evaluation. J. phys.Oceanogr., 16:390-394.

Large, W. G. \& Pond, S. 1981. Open ocean momentum flux measurements in moderate to strong winds. $\mathrm{J}$. Phys., 11: 324-336.

Mesinger, F. \& Arakawa, A. 1976. Numerical methods used in atmospheric models. GARP Publication Series. World Meteorological Association. v.1, 64p.

Orlanski, I. 1976. A simple boundary condition for unbounded hyperbolic flows. J. comp. Phys., 21: 251-269.

Pedlosky, J. 1979. Geophysical fluid dynamics. New York, Springer-Verlarg. $624 \mathrm{p}$.

Signorini, S. R. \& Miranda, L. B. 1983. Tidal and low frequency currents near the shelf break: Northeastern Coast of Brazil. J. phys. Oceanogr., 13:2107-2115.

(Manuscript received 11 August 1994; revised 16 October 1996; accepted 09 December 1996) 